Título do Trabalho

REFLEXÕES SISTÊMICAS SOBRE A JUREMA PRETA (Mimosa tenuiflora) COM ENFOQUE NO MUNICÍPIO DE SÃO JOÃO-PE

Nome do Autor Principal

Renner Ricardo Virgulino Rodrigues

Nome (s) do Orientador (a) (s)

Prof ${ }^{a}$ Drª Maria Betânia Moreira Amador

Instituição ou Empresa

UNIVERSIDADE DE PERNAMBUCO - UPE/Campus Garanhuns

Instituição (s) de Fomento

PIBIC-IC/UPE/CNPq/2013-2014

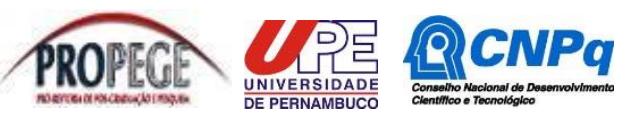

E-mail de contato

rennervirgulino@outlook.com

Palavras-chave: Jurema Preta. São João-PE. Sistemismo.

\title{
INTRODUÇÃO
}

Diante das observações realizadas sobre a composição da paisagem no município de São João, julgou-se pertinente refletir, de forma sistêmica, a paisagem verde rural do referido município através de uma discussão sobre a Jurema Preta, árvore típica do semiárido nordestino e vista com frequência e abundância na área municipal. Além disso, ela tem grande importância ambiental e econômica para os agricultores que se utilizam dela de várias maneiras. 


\section{OBJETIVO GERAL}

- Analisar a Jurema Preta (Mimosa tenuiflora) em sua abrangência local sob o ponto de vista ambiental, inserida na área rural do município de São João$\mathrm{PE}$, num contexto sistêmico, no âmbito das questões verdes da paisagem agreste.

\section{OBJETIVOS ESPECÍFICOS}

- Diagnosticar a utilização da Jurema Preta num contexto natural e econômico do município de São João-PE;

- Refletir sobre sua importância para a zona rural do município;

- Perceber como a população rural se relaciona sistemicamente com a Jurema preta presente em suas propriedades.

\section{METODOLOGIA}

O estudo está sendo realizado no município de São João-PE, localizado no Agreste Meridional, o qual faz parte do Semiárido pernambucano, distante $236 \mathrm{Km}$ do Recife. Destaca-se pela produção agrícola de feijão sendo considerado, atualmente, o maior produtor da região. A temperatura média anual é de 22,0 ${ }^{\circ} \mathrm{C}$.

A metodologia materializa-se pelo levantamento bibliográfico, bem como a ida a campo para observação. Também -se registros fotográficos para tomada de algumas cenas importantes para a pesquisa.

\section{RESULTADOS}

A Jurema-preta (Mimosa tenuiflora, (Willd.) Poir.) de sinônimo botânico Mimosa hostilis benth - leguminosa - "árvore de pequeno porte até $5 \mathrm{~m}$ de altura por $0,20 \mathrm{~cm}$ de diâmetro; casca escura com acúleos" (VASCONCELOS SOBRINHO, 1970, p. 76), é típica do bioma Caatinga, pertencente à família Fabaceae, da ordem das Fabales, 
ocorrendo nas regiões semiáridas do Brasil principalmente encontrada nos estados do nordeste brasileiro.

No espaço rural do município de São João-PE (figura 1), esta árvore se encontra em grande abundância. Ela é encontrada isolada ou agrupada onde recebe o nome de juremais, sendo vista em várias áreas (sítios) e compondo a paisagem do município e, por efeito, do Agreste de Pernambuco.

Este município destaca-se pela produção agrícola, sendo o maior produtor de feijão do Estado de Pernambuco. Outras culturas também são encontradas com grande produção, tais como o milho e a mandioca. Em relação a pecuária, São João se destaca pela criação de gado bovino para corte e leite, além de outras criações de ovinos e caprinos. Essas criações são comercializadas localmente, na "feira de gado de São João" e em cidades que fazem fronteiras, como Garanhuns - a oeste ; Jupi e Jucati - ao norte; Angelim - a leste; Palmeirina - ao sul, entre outras.

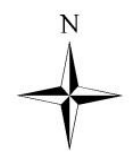

Mapa de Localização de São João-PE
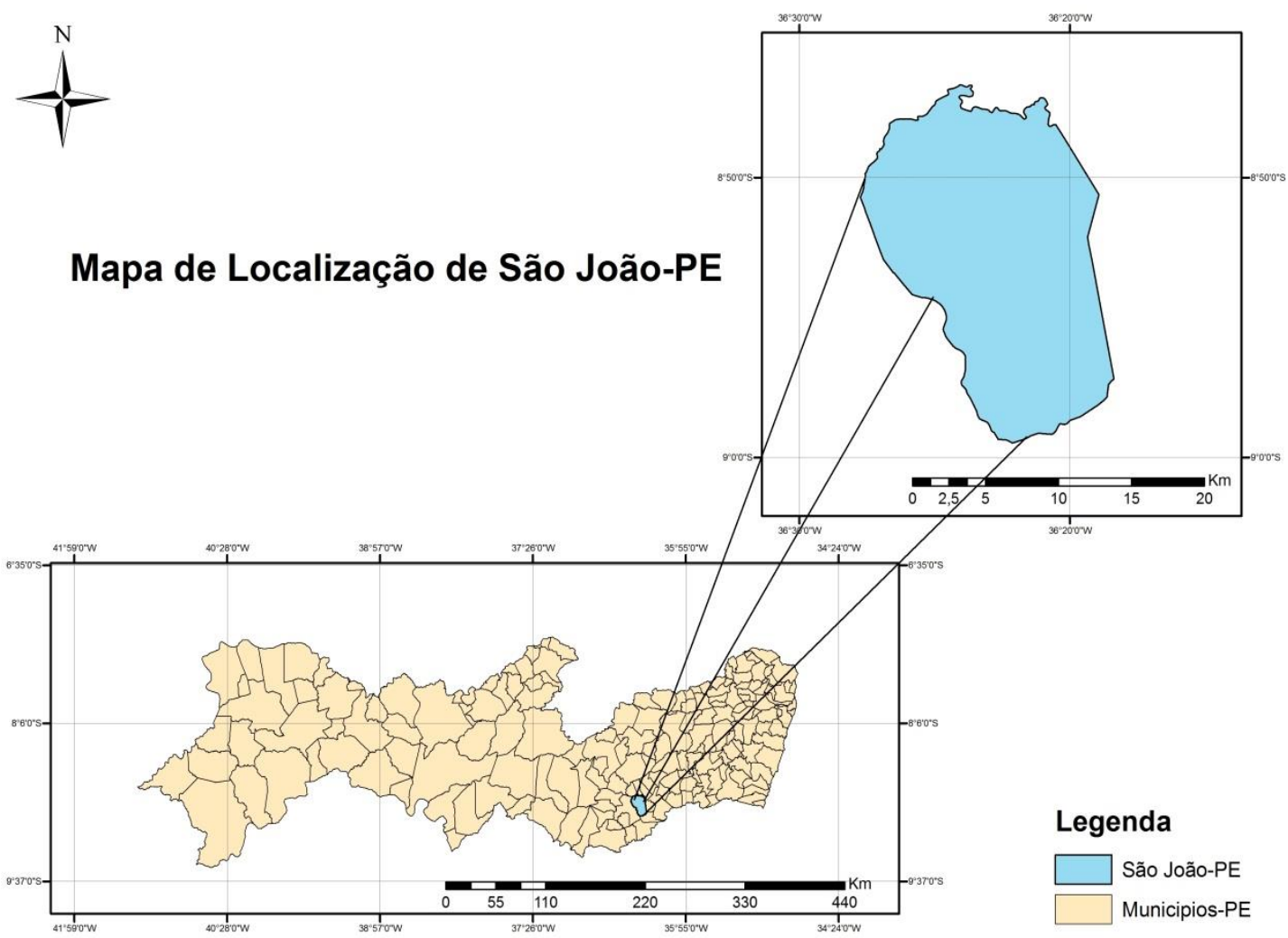

Figura 1: Mapa de localização do município de São João-PE. Fonte: Renner Rodrigues 


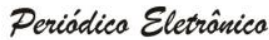 Fórum Ambiental}

da Alta Paulista

ISSN 1980-0827

Volume 9, Número 7, 2013

Expansão e

Produção Rural X Sustentabilidade

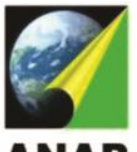

No referido município a Jurema-preta (figura 2), por ter madeira densa (densidade $\left.1,12 \mathrm{~g} / \mathrm{cm}^{3}\right)$, pesada e de alto valor calorífico possibilita aos os moradores da área rural utilizá-la de várias maneiras. Através do corte de seu caule eles transformam em estacas ou morões (figura 3) por apresentar uma grande durabilidade natural - depedendo de seu diâmetro quanto mais grosso, ele é denominado de mourão, quanto mais fino é chamado de estaca. Com esse material são construídas e feitas manutenção de cercas de currais, também usam-na para delimitação de território e de cercados para pastagens de gado bovino, ouvino, caprino e equino.

Da sobra da árvore, corta-se os galhos (lenha), os quais são deixados ao sol para secagem e, depois, são levados para casas-de-farinha onde serão utilizadas como combustíveis dos fornos movidos a lenha. Muitas vezes, essas árvores são erradicadas por inteiro, do tronco às raízes para abastecimento desses fornos. Também, quando erradicadas, são formadas "caeiras" ou carvoeiras onde são colocadas para produzir carvãos de alta combustão.

Outra utilidade da Jurema no município é a sombra para o gado, já que é comum ter a árvore em meio à pastagem e, em dias quentes, os animais descansam debaixo da sua sombra. Além disso, devido ao fato de que sua folhagem se mantem parte do ano verde, proporcionando um lugar agradável para os animais fazerem a digestão. Assim, a jurema preta é de grande importância para o sombreamento dos animais e para o solo (figura 4).
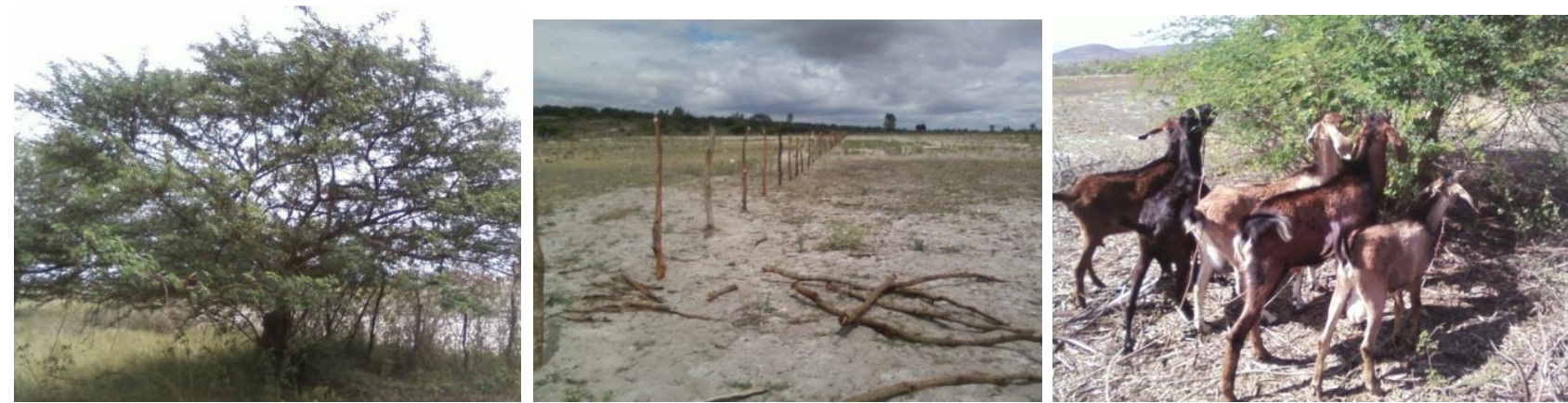

Figuras 2, 3 : Imagem mostrando a Jurema Preta, a utilização de estacas de Jurema Preta para delimitação de território e a utilização de sua sombra. Fonte: Renner Rodrigues, 2013.

Para melhor compreensão da importância da Jurema Preta na paisagem agreste rural de São João-PE, se adotou a visão sistêmica do pensamento complexo que segundo Amador (2011) "Pensar complexamente requer trabalhar com o objeto em 
contexto, ampliar o foco e conseguir visualizar sistemas amplos. Tira-se o foco exclusivo do elemento e incluem-se as relações" (AMADOR, 2011, p. 99). Assim, ao estudar a Jurema Preta busca-se a sua importância, bem como suas funcionalidades e interações com o local em que se encontra inserida.

Logo, verifica-se em Pena-Vega que "os sistemas vivos são sistemas abertos, o que significa que mantem uma troca contínua de energia com o meio para permanecer vivo" (PENA-VEGA, 2003, p. 32). E a Jurema Preta, ao realizar essa troca de energia com o meio proporciona sombra aos animais, retira $\circ \mathrm{CO}_{2}$ do ar e, devido a qualidade desua madeira, acaba sendo alvo para trabalhos que utilizam cerca e lenha.

Em estudos da terra se faz necessário que o homem tenha a noção do espaço geográfico, visto que as relações do meio se dão nesse espaço interrelacionado onde Morin (2005) cita: "O desenvolvimento das ciências da Terra e da Ecologia revitalizam a Geografia, ciência complexa por princípio, uma vez que abrange a física terrestre, a biosfera e as implicações humanas[...] A geografia amplia-se em ciência da terra do homem" (MORIN, 2005, p. 28-29). Essa ampliação da ciência da terra do homem deve-se ao fato do homem ser o maior trasformador do meio em que vive.

Essa relação geográfica é reforçada por Dardel (2011) ao escrever que, "a ciência geográfica pressupõe que o mundo seja conhecido geograficamente, que o homem se sinta e saiba ligado a Terra como ser chamado a se realizar em sua condição terrestre" (DARDEL, 2011, p, 33). Assim, o homem naturalmente interage com a paisagem, bem como a transforma a seu favor e bem estar.

\section{CONSIDERAÇÕES FINAIS}

Nesse contexto, mediante resultado das observações e do levantamento bibliográfico, pode-se concluir que a Jurema Preta é de grande importância para a população são-joanense, pois, ela pode ser utilizada de várias formas, tanto no aspecto ambiental quanto no aspecto econômico. No aspecto ambiental, ela pode trazer benefícios como: sombreamento para o solo e para os animais, e também, no processo de redução do $\mathrm{CO}_{2}$ na atmosfera local. Já no aspecto econômico, a Jurema - usada de maneira sustentável - pode ajudar na economia local, onde suas estacas podem ser 
vendidas e suas sobras destinadas aos fornos pelo seu alto teor calorífico para produção de farinha, produto muito comercializado no município e em outras cidades circunvizinhas.

\section{REFERÊNCIAS}

AMADOR, Maria Betânia Moreira. O pensamento de Edgar Morin e a geografia da complexidade. Revista Científica ANAP Brasil, n. 2, ano 2 - p. 60-76. 2009.

2011.

Sistemismo e sustentabilidade: questão interdisciplinar. São Paulo: Scortecci,

DARDEL, Eric. O homem e a terra: natureza da realidade geográfica. Tradução de Werther Holzer. São Paulo: Perspectiva: 2011.

MORIN, Edgar. A cabeça bem-feita repensar a reformar o pensamento. Rio de Janeiro: Bertrand Brasil, 2005.

PENA-VEGA, Alfredo. O despertar ecológico: Edgar Morin e a ecologia complexa. Tradução: Renato Carvalheira do Nascimento e Elimar Pinheiro do Nascimento. Rio de Janeiro: Garamond, 2003.

VASCONCELOS SOBRINHO, J. As regiões naturais do Nordeste, o meio e a civilização. Recife: CONDEPE, 1970 (Reimpressão,2005). 